\title{
PERSONAJES EN LOS BRAVOS: EL BUEN SAMARITANO
}

Gregorio C. Martin

\section{Ambiente y lugar}

Los bravos, de Fernández Santos, no cuenta con los estudios que podrían esperarse de una novela considerada unánimemente por la crítica como obra de mérito. ${ }^{1}$ Las mejores interpretaciones que de ella se han hecho figuran en trabajos de conjunto sobre la novela española moderna, los cuales, como es lógico, tienden a ser más un estudio general de Los bravos que a detenerse en un aspecto o personaje determinado de la obra. Me gustaría estudiar aqui los personajes de dicha novela, y en especial ese del médico, que salvo raras, rarísimas, excepciones ha sido considerado como el nuevo cacique de un pueblo.

Aunque la acción suceda en una aldea, no es esta una novela rural que pretenda describir la vida del campo - el autor critica la vida urbana siempre que tiene oportunidad. Lo que importa aquí son las consecuencias que las acciones del individuo y del grupo, junto con las pasiones humanas que las motivan, pueden tener en la comunidad. Tampoco podemos decir que haya protagonista, sino personajes que encarnan distintas posturas sociales de cuya relación resulta el modo de vivir de un pueblo. Un pueblo que no hay que olvidarlo - el resto del país ha abandonado a su suerte. Pero ese abandono y aqui lo sorprendente - no basta para que los escasos habitantes se solidaricen, sino que despierta en ellos las pasiones humanas: envidia, odio, orgullo, etc.

La obra comienza cuando dos personas, un hombre y un muchacho, llegan a la cantina de un pueblo. El hombre pregunta al dueño, Manolo, por el médico para que asista al muchacho que se ha cortado en un dedo. Esto es el primer apartado de la obra, que comprende con el segundo - donde se describe el lugar - algo más de cuatro páginas. El autor sienta en tan corto espacio las premisas del qué, quién, cómo y dónde. Por lo tanto, aparece en primer lugar la necesidad de curar, de que haya un médico, si bien el dedo herido del muchacho no es más que un símbolo. Esto es importante, ya que la verdadera enfermedad es esa otra que se percibe tras las conversaciones del primer apartado. He ahí lo que hay que curar: la abulia de un pueblo. Esto es evidente por la manera de actuar el hombre y Manolo. Para ellos el accidente del chico no supone nada que pueda alterar la rutina de todos los días. Incluso el miedo del muchacho se debe más a la inexperiencia de sus pocos años que a la conciencia que pudiera tener de su propia desgracia.

El médico, que ahora sólo puede terminar de cercenar el dedo herido del muchacho, es quien puede curar. Tendrá que decidir si acepta o no el sacrificio que tal misión va a exigirle. Para curar, como con el dedo del chico, el médico tendrá que cortar por lo sano 
cercenando aquello que no tenga provecho, aunque esté tan arraigado en el individuo como si formara parte de su naturaleza. Esto producirá una reacción contraria en los habitantes del pueblo, lo mismo que en el muchacho, como si su voluntad se opusiera al deseo de curarse.

Las casas, las fuentes y la carretera no cumplen con sus funciones urbanísticas del pequeño pueblo, sino que parecen ser partes aisladas de una naturaleza inhóspita en la que el hombre ha perdido sus facultades racionales para quedar supeditado a las necesidades orgánicas o a los impulsos del instinto. Baste tener en cuenta lo que hacen los habitantes de la aldea en el apartado tercero y cómo se los presenta. Antón, por ejemplo, piensa en su mujer cuando ve un burro revolcándose en el suelo. Al mismo tiempo, eso le trae a la memoria la imagen del cacique don Prudencio. "Ese no suda...," dice Antón refirién. dose al burro, y - repasando los nombres de las personas que ha de visitar para cobrar la cuota del médico - agrega: "don Prudencio"(14). Inmediatamente vemos al cacique en casa sin hacer nada.

El hombre es un prisionero de la naturaleza, pero tampoco aprovecha las escasas condiciones que le oferece para utilizarlas en beneficio propio. Cuando viajan al pueblo vecino, Pepe le dice al médico que aquello es distinto y que produce más. No obstante, el médico observa que también lo trabajan mejor(20). El río se desliza hacia el mar sin que nadie utilice la riqueza de sus aguas para regar el páramo. La aridez y la inercia parecen mantener una lucha silenciosa con el tiempo, un tiempo eterno que no necesita de relojes en un lugar donde todo es tan ajeno a la vida (dice el autor, pág. 12, que "el reloj aparecía inmóvil, falto de saetas, en una hora inverosímil ").

Parece que el destino de estas gentes fuera el de ser siempre fieles, como reza la leyenda del viejo escudo que Manolo colocara en su cantina; pero fieles a la idea de no tener destino alguno. Una vez que vieron alterada su rutina fue cuando sobre la aldea pasó aniquiladora la sombra de Caín. Luego todo volvió a su marasmo de pueblo vacío sin bienes materiales ni espirituales: "Era un pequeño pueblo sin iglesia, sin cura y sin riqueza"(13). Es el lugar donde el médico tendrá que cumplir la misión que le es exigida por sus conocimientos profesionales, y la que se impondrá a sí mismo por amor al prójimo.

\section{Los bravos}

Como ha dicho muy bien Curutchet, en esta obra no hay buenos ni malos, sino seres humanos con sus virtudes y defectos. ${ }^{2}$ Todos odian al cacique cuyo poder arbitrario y tiránico se opone al bien de la comunidad; pero todos, lo mismo que el cacique, tendrían si pudieran una amante como Socorro, según dicen Pepe (18) y Amparo (24).

Pepe y el médico son los que adoptan una postura social activa. Ambos limpian el motor del coche que el primero utiliza para subir el correo desde el pueblo vecino - un coche tan viejo como el pueblo - cuando aparece Antón, representante del secretario. Siempre soñoliento y cansado, Antón parece como si arrastrara el peso de su corpulenta mujer que lo persigue a todas partes. Con los otros habitantes del pueblo representa 10 que pudiéramos llamar postura social pasiva. Por él conocemos a Amparo, la joven que vive con la madre inválida. El padre desapareció cuando la guerra y ella tuvo que ocupar su lugar. Ahora, pasados los años, se ve destinada a vivir su soledad en la monotonía del 
pequeño pueblo. Critica (págs. 22-24) la vida que lleva don Prudencio, pero la verdad es que le gustaria ocupar ella el lugar de Socorro, la amante del cacique. Podría así recibir las atenciones que como ser humano necesita. Algo que la sacase de la "rueda," del monótono "girar" y "girar" entre la voz impertinente de su madre y el trabajo agotador de todos los días. En su desespero critica la vida de don Prudencio con Socorro, pero se entrega al desconocido que llega al pueblo (70). ${ }^{3}$ Esto es humano y no podemos censurar a Amparo por ello. Tenemos que estar de su parte al final, porque es doblemente engañada por el viajante, pero la única que acude a ofrecerle ayuda y cariño cuando lo ve derrotado. Y todo porque el viajante, como muchos hombres, se lamenta cuando es víctima, pero no se compadece cuando es verdugo; clama contra las injusticias que sufre, pero no contra las que ocasiona; se guía por la ambición, no por el amor y la solidaridad. Ante esto Amparo adopta una postura estoica: "La vida valía poco; era preciso seguir el curso de la rueda: girar, girar. .."(228).

No podemos estar de parte de Pilar, la solterona de cincuenta años que hace préstamos como don Prudencio y se siente objeto de murmuraciones: "Quizás ella era un poco como don Prudencio en su modo de ser, en el modo de aceptar los servicios de los demás como una obligación, como una pleitesía"(82). A vueltas con su inevitable soltería, no puede dormir. El remedio es un hombre, como sugiere Pepe (73), y Pilar que lo sabe mejor que nadie trata de que el médico sea ese hombre. Su comportamiento es ridículo y vulgar. Contrasta con su criada, vivaracha e ingeniosa, con la que mantiene Pilar una conversación que me recuerda mucho la de Fígaro con su criado en el famoso artículo de Larra. Con la diferencia de sexo, ambos sirvientes son asturianos y hablan como si fueran la conciencia de sus amos; burlones y mordaces les dicen lo que no les gusta oír. La criada de Pilar conoce las debilidades de su dueña y se burla de sus ridículas pretensiones; prefiere la sana alegría de su pueblo asturiano a éste que no tiene iglesia y donde "están todos muertos"(38).

Las demás mujeres del pueblo, las esposas, sufridas y silenciosas, no tienen el placer de la tertulia ni del vino como los hombres, pero comparten con ellos la dura tarea cotidiana. Ellas son en el pueblo, como dice el médico, "la descendencia, el placer y los hijos" (223).

De los hombres, Alfredo es un temerario. Como tal, no razona o razona tarde. No utiliza las aguas del río como un beneficio, sino como un riesgo al que se expone sin motivo. Por darse la satisfacción de pescar unas truchas burlando la vigilancia del guarda, está a punto de perder la vida y la seguridad de su familia. Pero ni las súplicas de sus hijas ni la cosecha sin recoger pueden hacerle entrar en razones. Sólo después, cuando había sido herido, "el dolor de la pierna le trajo a la memoria la cosecha sin recoger"(35);y entonces era ya demasiado tarde. Pero el descalabro no le hace más sensato y, tan pronto se siente recuperado, vuelve al río.

La postura de Pepe es más activa, como queda dicho, pero no más positiva. Aunque su trabajo es poco y cómodo, no le gusta lo que tiene, pero no sabe lo qué desea ni cómo conseguirlo. De lo único que está cierto es de que quiere disfrutar(19). No da dineroal viajante que llega al pueblo porque "al más tonto se le ocurre que nadie da duros a peseta" $(100)$, pero tampoco tiene valor para ir a desenmascararlo delante de todos y hacer un bien a sus conciudadanos. Todo lo contrario, se burla de ellos: "Nadie ignoraba que 
únicamente don Prudencio y él habían salido indemnes del fraude y gozaba con aquella admiración secreta, sin dar a los otros ocasión de desquitarse, sin concederles beligerancia, hiriéndoles con su ironía silenciosa"(208-9). Esto lo considera Pepe como la prueba que estaba necesitando para mostrar a los demás que él está capacitado para empresas más altas. Ahora todos tendrían que reconocer "su golpe de vista, podía considerar legítimas sus pretensiones a salir fuera, al mundo, lejos del pueblo, del coche y los palurdos viajeros que se veía obligado a transportar todos los días" (209).

Claro que Pepe no tiene ninguna razón para despreciar al prójimo que es, además, su conciudadano, y gracias al cual ha vivido. No debiera olvidar que es con el dinero de ese prójimo, su hermano, con el que piensa, como en los sueños de la lechera, levantar un castillo en el que se ve ya coronado antes de ganar un reino. Lo que Pepe ambiciona no es un trabajo más honrado y una vida social más justa, sino un mundo de vanagloria en el que se propone representar el papel de un chulo: "Un buen negocio en la capital, con el dinero que su hermano le prestaría, iba a llenar sus anhelos de siempre: anchos bulevares, dinero y sitios donde poder gastarlo, trato con gente fina, volver al pueblo por las fiestas con un traje nuevo y camisa de seda a holgar unos días relatando sus hazañas"(209). No pretende resolver su futuro mediante el esfuerzo y la dedicación organizándose mejor, sino que todo lo confía a la buena suerte, al matrimonio ventajoso, etc., que le resuelva la vida de la mañana a la noche. El dinero no haría a Pepe más generoso con sus antiguos conciudadanos, sino que le envanecería hasta el extremo de pasear su riqueza ante ellos haciéndoles más conscientes de su desgracia.

Pero las vanaglorias le duran a Pepe hasta que se desvanecen sus sueños de riqueza. Esto sucede cuando alguien le prueba que en la capital también hay Prudencios y se unen para crear monopolios que enriquecen más al rico, hacen más pobre al que ya lo es y niegan una oportunidad al advenedizo(220). Pepe reconoce entonces que las cosas pueden parecer de una manera y ser de otra, pero su orgullo no le permitirá jamás aceptar ante los suyos el fracaso, si acaeciera, y se propone "no volver nunca si la fortuna le volvía la espalda" (229).

\section{Los visitantes}

Una prueba de que lo que interesa aquí es lo social, y no el lugar ni unos personajes determinados, la tenemos en el curioso individuo que llega al pueblo (44) interesándose por las truchas del río - luego sabremos que se trata de un pescador de dinero. No tiene nombre y no hace falta que lo tenga; lo que importa es su actividad en la sociedad y las consecuencias de sus acciones. El autor describe con detalle el aspecto de este hombre y cómo ejerce su misión. Insiste en su indumentaria (ropa negra, cartera negra, zapatos viejos y rotos) y en las gafas que lleva $(45,54,56,61,107)$, las que limpia y ajusta constantemente, como si se tratara de un ave de rapiña que estuviera siempre ojo avizor sobre su presa. El de los zapatos, así se lo llama varias veces, conoce muy bien las flaquezas humanas (codicia, lujuria, envidia, vergüenza) y sabe cómo utilizarlas para lograr lo que persigue. Cuando haya pasado por el pueblo habrá sido como un espíritu maléfico que hechizó a todos, les sacó sus ahorros y dejó tras de sí el caos. Al final, al verle descubierto y derrotado, hay que tenerle compasión como a ser humano - es lo que hace 
el médico -, pero no podemos perdonarle que, en lugar de solidarizarse con los demás contra la injusta distribuición de la riqueza o la falta de una oportunidad para ganarse la vida, roba a los que no tienen dejándolos en la miseria. Para él no importa el bien de la comunidad, sino el particular suyo, aunque sea a costa del prójimo que apenas tiene para vivir, y eso no tiene perdón. Parece incluso como si el autor quisiera a veces presentar a este personaje desprovisto de sentimientos humanos, reduciéndolo a vegetal o cosa. ${ }^{4}$ Claro que al final se preocupa porque una mujer reciba cierta cantidad de dinero, pero entonces se trata ya más de destacar el valor humano del médico.

¿Y qué decir del cura que viene del pueblo vecino para la boda de Antonio el herrero? Es un hombre sin vocación y sin fe, que ejerce las funciones de su ministerio por rutina y de prisa, como un funcionario cualquiera. Él es un ejemplo más de falta de solidaridad humana, de individualismo y de falta de espíritu ("No le importaban las cosechas de aquellos hombres, ni las tierras que fuera a reunir el nuevo matrimonio," pág. 123). Olvidando que nada se gana sin esfuerzo en este mundo - que es también la doctrina de Cristo para el otro - se rindió enseguida a las dificultades que encontró para ejercer su apostolado y ahora vive una vida de burgués. No es buen pastor, porque dejó que el rebaño marchara a su suerte rechazando el sacrificio de guiarlo. Para él la religión es teoría (la doctrina, los ritos), no práctica. Ahí está su error, Por eso no comprende cuánto vale el gesto de un niño que le ofrece agua cuando llega sudoroso al pueblo(118), y,en lugar de darle las gracias, le reprende por no saber la doctrina. No se da cuenta que la verdadera doctrina es la que está en el corazón humano: dar de beber al sediento. La otra mal la puede' aprender un niño que tiene que trabajar de sol a sol como su padre para poder vivir. Si el apostolado no puede ejercerse en ese pueblo porque no hay casa nueva, como dice el cura (126), mal puede un niño aprender una doctrina sin apóstoles que la practiquen. Crecerá, como han crecido ya muchos de sus mayores(105), con la certeza de que nada puede esperar en la vida que no venga de sí mismo.

\section{El cacique}

Don Prudencio es el cacique. Su postura social es negativa. Su presencia es pocas veces vista, pero siempre sentida. Toda su vida don Prudencio ha sido prudente, como su nombre indica, y generoso. Estas dos virtudes, que él ha interpretado como sinónimos de coacción y usura, le han hecho dueño del pueblo. Siempre ha sabido hacer buenos negocios en malos tiempos. Con su prudencia no denunció a los que quisieron matarlo cuando la guerra, y ahora deben la vida al prudente silencio de don Prudencio. Amparo lo dice cuando habla del viejo con Antón, tal vez sin comprender la importancia de lo que ha dicho: "Tanto hablar de él, tanto ponerle verde a sus espaldas y cuando vais a su casa; con dos palabras y un cigarro os engatusa y jse acabó!, como si le debierais la vida" (22-3). Esos vecinos han de ser dóciles al cacique y no incomodarlo, o les irá la vida en ello. Con su generosidad, entendida al modo de don Prudencio, ha prestado miles de duros en los años de malas cosechas. Los vecinos comprendidos en este grupo cumplirán fielmente las condiciones que imponga el cacique, o les irá la subsistencia en ello.

Pero la muerte se acerca ya a don Prudencio. El autor lo introduce sugiriendo indirectamente lo que después será un hecho. Socorro dice al cacique que "se queda la casa sola" $(85)$ porque ella va a salir; el amo le dice que pida el coche a Pepe porque quiere ir a la 
capital; en la capital le dirá un médico su incurable enfermedad; cuando vuelva de la capital (137) encontrará la casa sola porque Socorro se habrá ido a vivir con el médico.

Pero antes de ir a la ciudad a conocer su destino, don Prudencio da un paseo por el pueblo. Él no lo sabe, pero será el último. Preocupado en amasar su riqueza con el sudor de otros, ha vivido ajeno al pueblo que ahora considera miserable. Una miseria a la que tanto ha contribuido pudiendo remediarla. Pudo haber sido el buen pastor de ese pueblo, pero se aburría esperando la hora de la cena porque "no tenía ovejas que guardar ni grano que recoger" (97). Para el pueblo ha sido una desgracia tener un hijo así, que es exactamente lo que él piensa del hijo de Amador. El chico, inválido, pasa los días en la cama entre delirios, sudor y desespero. Su incurable enfermedad consume cuanto el padre gana. Prudencio también ha sido un inválido toda su vida, pero voluntario. Nunca lo han visto trabajar en nada, y con su caciquismo consumió los exiguos frutos que los vecinos obtenían trabajando de sol a sol en las áridas tierras. No necesita descansar al anochecer, su única preocupación es irse "a dormir comn todos los días, en espera de ver el amanecer del siguiente" (96). No sólo no ha contribuido al bien social del pueblo, sino que lo ha perjudicado. Las dos oportunidades que le quedan de cooperar con sus vecinos - la boda del herrero y advertirles de la estafa del viajante - las desprecia y se marcha a la capital.

Don Prudencio no disfruta en la capital como otras veces. Tiene un presentimiento que le deprime. Es el principio de su fin. Abandonó a todo el pueblo para confiarse sólo a su hermano, y ahora descubre que ese hermano lo abandonó antes de oír el diagnóstico de su próxima muerte, al que ha de enfrentarse solo. Piensa entonces que por lo menos en el pueblo hay una persona, Socorro, que lo quiere; pero cuando vuelve a su casa descubre que también ella se ha marchado librándose de su humillante tutela. Al llamarla, “¡Socorro!”(137), esa palabra es más que el nombre de la muchacha. Es la voz de un hombre que se ve solo ante la presencia amenazadora de la muerte, y le gustaría recibir la ayuda y el consuelo que sabe no merece. Suenan entonces once campanadas en el reloj de la casa anunciando el próximo fin de una jornada, símbolo premonitorio para don Prudencio que las oye. Curioso contraste ahora con el hijo de Amador que aparece en el próximo apartado: El chico desearía morir, Prudencio daría cualquier cosa por tener más vida; el muchacho descubre la mentira de los que le rodean, Prudencio la suya propia que le ha llevado a engañarse a sí mismo. Lo trágico es que el niño es víctima de un destino injusto, mientras que Prudencio recibe el destino de su injusta vida.

Ahora comprende Prudencio que el pueblo que ha dominado por años le sobrevive, y él, que se impuso a tantas cosas, no puede hacer nada por evitarlo. Su agonizar es lento. Poco a poco ve desvacer los resortes de su autoridad; y no porque otro se la quite, sino porque él es incapaz de ejercerla. Es como si la naturaleza, con su lenta evolución, se encargara de hacer justicia desposeyendo a Prudencio de todo, igualándolo a sus sumisos conciudadanos antes de entregarlo a la muerte. Intenta aún disimular su debilidad ocultándose de los otros ("se escondía de sus vecinos," pág. 204), pero el pueblo quiere ahora ser testigo voluntario de su caída, como antes lo fue forzoso de su opresión, y Antón viene de vez en cuando a tomar nota de su agonía para contarlo a los demás en la taberna: "Había en sus ojos un afán investigador, como una curiosidad científica que no se cuidaba en disimular, por seguir el curso de la enfermedad hasta el desenlace que, seguramente, juzgaba próximo. Preguntaba por la enfermedad en general, por los 
síntomas, y el viejo podía ver cómo mentalmente lo anotaba, sin duda, para facilitar el parte a la noche en la cantina" (205).

Antón se permite ahora con el viejo libertades "que en otros tiempos ni hubiera soñado siquiera" (205); no porque esté ganando valor, sino porque el cacique está perdiendo vida $y$, al contrario de antes, se conforma con odiarlo sin tomar represalias, con aparentar una vitalidad que no tiene: "Y porque veía en aquel hombre al pueblo entero presenciando atento su agonía, procuraba bajar todos los días, aun a costa de grandes esfuerzos, a ocupar el sillón" (205). Pero el pueblo, que ha sufrido tanto por no tener nada, ve ahora con desdén cómo Prudencio sufre por tener que dejarlo todo. Él trata de recordar los días de su infancia, pero, como es un hombre aferrado a la materia, le aburre todo lo que sea sentimentalismo y no recuerda siquiera la cara de algún antepasado (206).

Como en casi todos los personajes de esta obra, el orgullo de don Prudencio es superior a todo lo imaginable: superior a la razón, a los sentimientos familiares y al deseo de vivir. ${ }^{5}$ Es un exceso de orgullo lo que le precipita antes a la tumba por no dar al médico la receta que el especialista le entregara. Cuando don Prudencio descubrió que Socorro se había ido con el médico dejándolo a él, "inconscientemente se llevó la mano a la cartera donde seguía guardando la receta"(138). No llamaría al médico aunque le fuera la vida en ello. Unos días más tarde, la nota que le habían dado para el médico no había salido de su cartera (206). Su orgullo era más fuerte que el deseo de curarse: "Más tarde venía un dolor agudísimo y repentino, los ahogos y desmayos que le derribaban sobre la cama, exánime, luchando por vencer a su cuerpo, a la enfermedad, al orgullo que le impedía llamar a Antón y a su mujer, pedir auxilio, salir al balcón y gritar al pueblo que se moría, que tenía miedo, que llamaran a un médico"(207). Y prefirirá vivir menos por morir orgulloso.

El cacique odia al médico con un odio, dice, "pleno de rencor"(206), que no es como el que siente por los otros. El médico se enfrentó a él sin temerlo, se solidarizó con los demás vecinos, con sus trabajos y preocupaciones, como el mismo Prudencio comprendió cuando "pensó en el médico, un médico que ayudaba a Pepe a desmontar el motor del coche"(97). Y es por eso, por esa solidaridad del médico con los vecinos, por lo que el cacique lo odia más. Es eso lo que él pudo y debió haber hecho, pero no hizo. Perdido su poder y el temor que infundía, Prudencio comprende que a la hora de la verdad su vida ha sido un total fracaso. Pensó que "sabía aconsejarse bien para los negocios y esconderlo cuando hacía falta, como en la guerra," cuando escondió un arca con todos sus caudales (97), y ahora ve que esa fortuna - amasada con el sudor ajeno - no le vale para comprar un amigo que le acompañe en la hora de la muerte. El mismo que durante años administró sus negocios en la capital con tanta habilidad como el que sabe que a la larga administra para sí, su hermano, disfrutará de la riqueza que Prudencio acumuló. Y su hermano lo abandonó por prejuicios humanos: orgullo de sangre, piensa Prudencio. Entonces él, para no faltar a tan sagrada herencia, decide morir "sin pedir consuelo a nadie, ni a su hermano, ni a sus vecinos" (207).

El cacique comprende en su lento agonizar que su vida ha sido inútil para los demás y para sí mismo, porque ahora no puede recibir el amor que no ha prodigado. Por no darse a los demás cuando pudo, ellos lo ignoran cuando no puede, y esto lo exaspera: "Los desdenes de éste [su hermano] los volvía hacia los otros, tratando de dar salida, 
fuera de sí, a la ira, el despecho, la amargura de que su proceder y la huida de Socorro le habían colmado"(207). Y cuando hace este balance de su vida le llega el de su cuenta corriente en el banco. No se molesta en mirarla. De nada le vale que sea positivo. En el mundo que le espera no se compra poder con usura, sino con la verdadera solidaridad humana. Y en eso el balance de Prudencio es completamente negativo. A él, tras su muerte, parecen destinados aquellos versos del poeta:
Alguien dirá: “¿Qué dejaste?”
Yo pregunto: “¿Qué llevaste
al mundo donde hoy estás? ”

\section{El buen samaritano}

Al buen tacto del autor se debe que el personaje del médico sea perfectamente aceptable. No se trata de un arquetipo, de un ser lleno de virtudes. Es un hombre que descubre su misión social mediante la experiencia, la incertidumbre y la reflexión. Lo vemos vacilante al principio, pero no en cuanto a ejercer su profesión, sino por lo que piensan los demás de cómo la ejerce - corta el dedo del muchacho, pero no está seguro de que él y su padre lo consideren la única solución(11). Se debe a que se ve sólo como médico; no ha concluido aún el proceso de integración dentro de la pequeña comunidad en que vive. Llegará a su tiempo, y ahí el tino del autor.

Cuando Alfredo aparece herido de un balazo, el médico lo cura y no lo denuncia. Al no hacerlo y darle asistencia se ha hecho cómplice, colocándose al margen de la ley, con el consiguiente riesgo profesional y personal que eso suponía. No podrá usarlo en el futuro como coacción porque él mismo sería reo. Esto lo diferencia inmediatamente de don Prudencio. El médico se pone aquí del lado del prójimo que más sufre, como dirá más adelante(198), y a cualquiera se le ocurre que con una ley que considera la vida de un ciudadano menos importante que la de un pez el que más sufre es el hombre.

El médico cumple con eficiencia su deber profesional visitando enfermos a cualquier hora del día ("Aquí nadie se movería por una cosa así a esta hora," dice la mujer de Manolo, pág. 47, cuando el médico visita al hijo inválido de Amador al mediodía). En una de esas visitas lo llama don Prudencio para que vea a Socorro. El cacique lo conduct hacia la casa dándole golpecitos hipócritas en la espalda y lo invita a probar sus frescas lechugas - esto resultará irónico cuando el médico le quite después a Socorro -, pero es importante notar que al médico no le gusta don Prudencio ni aprueba sus métodos antes de sentirse atraído por la criada. Eso quita todo posible rencor por causa de la joven.

La llegada del viajante permite comparar al médico con Pepe y con don Prudencio. Su opinión del negocio que aquél propone es clara y definitiva: no le parece muy seguro. $\mathrm{Y}$ así lo dice cuando le preguntan(66). A Pepe tampoco le parece seguro (99-100), pero gracias a la estafa consigue al final que su hermano le preste el dinero que necesita para emprender nueva vida. Como de rechazo él se ha visto favorecido, "casi le estaba agradecido al viajante porque a pesar de la pérdida que para su hermano suponía la estafa, con toda seguridad ahora se hallaba mucho más dispuesto a que quien había visto más claro que él marchara a la capital y saliera adelante con la ayuda de su dinero"(209). Don 
Prudencio es el más hipócrita. Nunca ayudó a nadie, y no va a hacerlo ahora que tiene la oportunidad de verlos a todos víctimas de su usura, que será lo que pase cuando el viajante les robe sus ahorros. Así es que Prudencio, aunque está seguro que no va a dar su dinero, miente cuando le pregunta la mujer de Martín buscando su consejo, y dice que no sabe qué hará(84). Una palabra suya hubiera despertado la desconfianza en los vecinos salvándolos de la estafa; pero oculta su intención aunque luego le dirá al viajante rotundamente que no(93), y se regocija y envanece pensando que él es el único que se libra del robo (97).

El médico cumple una función dentro de la comunidad de la pequeña aldea. Le gustaría ser considerado como uno más dentro de la estructura social, pero su profesión, tanto cuando la ejerce como cuando no, crea una barrera que hace que los otros vecinos lo consideren diferente y superior. Es aún pronto para saber si le gustaría quedarse allí aunque al enamorarse de Socorro se siente más unido al pueblo - y así se lo dice a Alfredo, "porque era pronto para sentirse a gusto o no, para odiar o amar aquel pueblo" (159). Encontrará la respuesta, lo mismo que Moisés, cuando suba a la montaña.

A partir de ese momento la novela gana muchísimo y, en mi opinión, no puede entenderse el desarrollo psicológico del personaje del médico y su valor humano si se ignora el episodio en la montaña con los pastores. Ya el autor lo coloca en el apartado más extenso de toda la obra ( 28 páginas) junto con el prendimiento del viajante, en el que el médico interviene ya de una manera decisiva como consecuencia de sus reflexiones en la montaña. Aquí, mientras asciende al chozo del pastor enfermo, considera las dos opciones que tiene en la vida: ejercer su profesión en la ciudad, o ejercerla en el pueblo. De ambas escuchó defensores y detractores durante los últimos años de su carrera: "Hazme caso; tú no sabes lo que es eso; si eres de allí, todavía; pero a uno de fuera y joven como tú no le hacen maldito el caso. Mira que yo sé lo que es; te pagan mal y cuando quieren; siempre andan con el cuento de que no tienen dinero. Desengáñate, chico, los buenos médicos se ven en los hospitales"(179). Eran los que "durantelos últimos años bien se habían movido, halagando, trabajando el terreno de firme" (183), y se casaban con las hijas de los patrones para heredar la clientela y continuar la estirpe(179). En otras palabras, eran los que perseguían la buena vida sin importarle el prójimo que usaban para sus fines. Junto a ellos estaban los otros, los que le aconsejaban: "Por lo menos vete a un pueblo rico, un pueblo grande donde haya dinero. Tú tienes tu carrera y ya habrá alguna que ponga su capitalito. Te casas y en paz, a descansar. Que si un poquito de brisca por las tardes, que si las fiestas, que si la matanza; los congresos en Madrid. . . Ese amigo de tu padre no sabe lo que dice. ¿Que los buenos médicos están en Madrid? Yo me río de los buenos médicos" (179-80). ¡ Qué poco se diferenciaban de los anteriores! Todos perseguían la fortuna fácil mediante el matrimonio ventajoso.

El médico estaba ahora haciendo estas reflexiones en un monte, y el lugar más próximo, que ni siquiera figuraba en el mapa, se encontraba a varias horas de camino. Todo lo contrario de lo que le recomendaran sus compañeros. $Y$ estaba allí porque iba "a la busca de un hombre enfermo, de un pobre y desconocido prójimo" (180). Ese prójimo le da de comer lo que tiene y él le asiste con lo que sabe. Hay una perfecta armonía entre el hombre del campo y el hombre de la ciencia porque ambos se ven como seres humanos con todas sus limitaciones. "Había huido de la ciudad al pueblo, y ahora huía del 
pueblo también," insiste el autor, y prefería estar allí donde estaba su prójimo enfermo, visitando a ese prójimo y curándolo como en el Evangelio, cuya doctrina parece seguir tantas veces esta obra. Eso es solidaridad humana; y para que la haya hay que olvidar el odio del pasado; y a ese mundo viejo y próximo a la muerte que lo representa, como don Prudencio, hay que compadecerlo porque es muy tarde para cambiarlo y en él también está el prójimo, "en el pueblo, viejo y solo, odiado por todos, encerrado a cal y canto en su casa" (185).

Para mí eso justifica el valor humano del médico, que da así un ejemplo de solidaridad y de responsabilidad social en armonía con la obra, que es un ejemplo de amor y desamor, y en contraste con la vida del burgués y del cacique, que buscan su mejor mundo sin solidarizarse con nadie ni responsabilizarse por nada. Yno es que el médico sea una persona llena de virtudes. Es un ser humano con las flaquezas de tal. Por eso, siempre que pensaba en el cacique "sentía cómo su alma se replegaba en sí mismo, encerrando el corazón en el frío límite de su propio ser" (185).

En Los bravos la ley no se impone porque sea justa, sino por venganza ("Alguien lo va a pagar," dice el guarda del río, pág. 27); los encargados de hacer obedecer la ley actuan sólo por temor al superior $(87,234)$. Esta falta de organización contrasta con el orden que tiene el pastor en su trabajo. Él tiene también quien le ayuda a conducir su rebaño y a guardarlo. Son dos clases de perros. Uno es pequeño, pero infatigable, laborioso, eficaz; sabe dónde tiene que ir el rebaño y lo conduce con precisión. Los otros son dos grandes mastines que no se mueven del chozo; útiles para la defensa o el ataque, pero sin habilidad para la otra misión, uno de ellos ha llegado a matar una borrega (186). El pastor ha dado a cada uno el trabajo que mejor puede cumplir. Es como un símil del buen gobierno. Los que gobiernan debieran ser buenos pastores y saber rodearse de dirigentes capaces de inculcar en el pueblo el amor y la justicia, y de llevarlo, como el buen pastor a su rebaño, por la senda de la prosperidad social, no de la discordia.

El médico ve ese orden y habla con el pastor de su vida tranquila en la montaña ("Para mí no hay cine ni teatros; a mí deme un sitio como éste, desde donde se abarque mucho terreno, y no quiero más," dice el pastor, pág. 187). Y, como en la obra de Cervantes, en contraste con ese mundo está el de las discordias, la guerra civil, el ser humano aniquilando a su prójimo. " ¡Y que en esto venga a parar un hombre...!, recuerda el pastor que le oyó decir a su padre en aquellos días que ahora evoca con el médico (189).

Luego son los hombres los que crean la discordia en el mundo, porque se dejan llevar de la ambición y del odio. Por ambición roban, y por odio matan. El médico lo ha visto en el pueblo y el pasado lo prueba con la guerra. Pero piensa en Socorro, que lo ha sacado de "la insatisfecha, dolorosa soledad de antes" (190), y piensa en la paz que siente atendiendo a un pobre enfermo. Esa es la ley que él halla en la montanña: la del amor al prójimo, que es también una ley divina, como lo prueba el episodio de Cristo y la pecadora que la obra - el Evangelio una vez más - sitúa en su ambiente geográfico. Sólo la pecadora dio posada a Cristo en el pueblo de Isoba (Hay una aldea con este nombre en la provincia de León, municipio de Lillo) y por eso salvó su casa del castigo divino. Es un poco lo que pasa en la obra con Socorro y el médico, y con Amparo y el viajante. El autor parece haber elegido con intención los nombres de estas mujeres. 


\section{Personajes en Los Bravos}

Seguro de que hay que amar al prójimc como a uno mismo, el médico baja de la montaña. Tendrá pronto oportunidad de saber lo difícil que es practicar ese amor, porque abajo el pueblo se preparaba para linchar al hombre que aniquiló en un día lo que los vecinos acumularon en años, un hombre que no amó a su prójimo. Se trata de un caso de justicia o venganza. El médico puede elegir entre mantenerse estrictamente en su papel (199), como han hecho los médicos que le precedieron, o pensar que además de médico es un hombre socialmente responsable que debe defender la fuerza de la razón contra la razón de la fuerza. Claro que es fácil llamar al orden cuando no se ha perdido nada, o permanecer al margen dejando que la responsabilidad caiga en otros, como hace don Prudencio. El médicoes consciente de ambas posiblidades, y de que "no era valiente, ni abnegado," pero tenía "un buen corazón y por ahí la vida le tenía cogido" (199). Hay un hombre derrotado del que se ha hecho cargo, y puede entregarlo a los vecinos, deseosos de venganza, o curarlo y entregarlo a la justicia. Como en el caso de Alfredo, el médico se pone del lado del prójimo que más sufre. La novela, maravillosamente estructurada en cuanto al desarrollo psicológico del personaje del médico, comienza salvando a un hombre para el pueblo quitándoselo a la ley, y termina entregando un hombre a la ley quitándoselo al pueblo. Dos conclusiones distintas, como distintas son las circunstancias que las motivan; pero ambas evidentemente justas. En las dos el proceder del médico es moralmente ejemplar.

Es un gran error considerar ese episodio con el viajante como una prueba de que el médico es el futuro cacique del pueblo. Evitar que linchen a un hombre no es una prueba de caciquismo, sí de elementales principios humanos. Lo que preocupa al autor es el hombre con sus virtudes y defectos. De ahí que el médico no sea un ser lleno de perfecciones, lo que restaría valor al personaje. Tenemos que verlo a través de sus reflexiones, de sus dudas y de sus debilidades, que nos explicarán su modo de obrar, y compararlas con las reflexiones del cacique don Prudencio. Sabemos que el pasado de éste ha sido la coacción y la usura. El médico se solidariza con Alfredo cuando está herido porque es el que más sufre; Prudencio piensa que así aprenderá Alfredo "de una vez cómo las gasta el guarda" (91). El médico dice lo que piensa del negocio que propone el viajante; Prudencio lo oculta y luego goza pensando cómo el forastero estafa a sus vecinos. El médico sale con Alfredo y con Pepe, ayuda a este a limpiar el motor del coche (lo que sorprende inmediatamente a Antón que piensa que los otros médicos no tenían esas costumbres, pág. 14) y habla con todas las personas del pueblo; Prudencio no conoce a los niños de un pueblo de setenta habitantes en el que ha vivido siempre (95), no comunica con nadie, no participa en los pequeños acontecimientos sociales y no permite que nadie viaje en el coche de Pepe cuando él. El médico no reclama cuando nadie le nabla en el pueblo porque lo considera "poco digno," no compra nada en la cantina de Manolo porque le parece "absurdo gozarse en un necio capricho" de ponerlo en evidencia ante los otros vecinos, no piensa que le va el orgullo en ello, sino que los otros están equivocados, y está dispuesto a demostrarles que nunca estuvo su corazón más cerca de ellos que cuando evitó que lincharan al viajante (211-12). Don Prudencio no reflexiona nunca de esa manera, jamás hubiera intervenido para salvar al viajante cuando no le iba nada en ello, no hubiera dejado su casa para ayudar a un pobre enfermo en la montaña, ha sido un hombre huraño, vengativo, dominado por la ira, el despecho y el orgullo que le impiden pedir ayuda cuando se siente morir. Don Prudencio es el muido tal como no debe ser, y 
el médico es el mundo como nos gustaría que fuera. Lo que está en perfecto acuerdo con las ideas expuestas por el autor repetidas veces.

Cuando luego alguien dice en el pueblo vecino que el médico se hará dueño de la aldea, hay que tener en cuenta que alguien más ha dicho inmediatamente antes: "Está bueno, hombre, que tengan que venir de fuera a enseñarnos cómo hay que hacer con el viejo. Um médico así nos hacia falta aquí, no el carcamal que nos mandaron" (217). Y no es la primera vez que en la obra se insiste en la diferencia entre este médico y los más viejos, que exigían les trajeran los enfermos a casa(183), que no hacían caso de los vecinos (159), que no comunicaban con ellos (14).

No podemos ignorar quiénes son los que acusan al médico de caciquismo: Pedro, el dueño del bar en el pueblo vecino, y, principalmente, Cesar. La falta de discreción de este último se ve por cómo le pinta a Pepe la vida en la ciudad - de la que no tiene ninguna idea -, en contraste con un viajante que le prueba que para vivir en la ciudad hay que trabajar como en todas partes.

Cuando descubren al final que don Prudencio está muy grave, el médico, aun sabiendo que el cacique lo odia, rompe con prejuicios humanos y se acerca a darle la última asistencia. Cumple así lo que pensara en la montaña(185) de que el prójimo era también un viejo odiado por todos que no salía de su casa. Luego el médico compra esa casa porque los hombres del pueblo, que no supieron unirse contra quien los esclavizó, se unen contra el médico que es el único que desea ayudarles. Por eso Baltasar, que estuvo muy satisfecho de alquilarle una casa suya un mes antes, lo pone en la calle sin tener valor para decirle el verdadero motivo. El médico se ve así obligado a vivir en la casa del cacique porque es el único lugar que le queda, como Cristo se vio obligado a refugiarse en casa de la pecadora de Isoba. Allí sólo puede sentarse a esperar "la primera ocasión de acercarse un poco a la otra orilla" (221) y demostrar al pueblo que la casa del tirano será en el futuro casa de socorro. No se trata de huir, sino de unirse. Por eso que mientras Pepe marcha del pueblo prometiendo no volver, el médico se propone dar vida al pueblo quedándose. Es la misión que se ha impuesto por amor al prójimo, por ser, como ha dicho sutilmente Gonzalo Sobejano, un buen samaritano. ${ }^{6}$

Romance Languages

Wake Forest University

Winston-Salem, USA 


\section{NOTAS}

${ }^{1}$ Jesús Fernández Santos, Los bravos (Barcelona: Ediciones Destino, 1969). Cito siempre por esta edición, con números arábigos y en el texto.

${ }^{2}$ Juan Carlos Curutchet, Introducción a la novela española de postguerra (Montevideo: Editorial Alfa, 1966), pág. 116.

${ }^{3}$ Hay que notar en este momento la presencia de los caballos, como cuando Socorro acepta al médico (64).

${ }^{4}$ Dice el autor en la página 61 que se trataba de un hombre "tan ajeno a la tierra, al río, al pueblo entero, como una extraña planta que el mes de calor hubiera hecho brotar junto a la fuente." Y en la página 93 lo presenta así: "Eran unos zapatos viejos, cortados en los costados, y sobre ellos un hombre... Los viejos zapatos anduvieron calle abajo ..."

5 Orgullo tiene Alfredo (127), que no permitirá que sus hijas vayan a servir a otros para resolver su vida, aunque él vive malamente. $\mathrm{Y}$ orgullo tiene Baltasar, que dejó que una hija muriera en la soledad y la miseria en un hospital antes que perdonarla por haber escapado de casa (128).

${ }^{6}$ Gonzalo Sobejano, Novela española de nuestro tiempo (Madrid: Editorial Prensa Española, 1975), pág. 324. 